\title{
Identification of Plastome Variants useful for Cytoplasmic Selection and Cultivar Identification in Onion
}

\author{
Josefina Alcalá, ${ }^{1}$ Leonard M. Pike, ${ }^{2}$ and James J. Giovannoni ${ }^{3}$ \\ Vegetable Improvement Center, Department of Horticultural Sciences, Texas A\&M University, College \\ Station, TX 77843-2133
}

\begin{abstract}
AdDitional INDEX wORDS. Allium cepa, cytoplasmic male sterility, intraspecific variation, noncoding chloroplast region, sublimons

ABSTRact. The relatively low evolution rate of the chloroplast DNA has made it an ideal tool to study evolutionary processes in plants above the species levels. However, recent studies have demonstrated that intraspecific variation in the chloroplast DNA is also common. This variation has provided useful insights into population level evolutionary processes. The polymerase chain reaction and sequencing of a noncoding chloroplast region used to classify onion lines for cytoplasmic type facilitated the identification of one sterile and two normal plastome variants in onion (Allium cepa L.). Sequence comparison revealed that differences between plastome variants included the presence of single-nucleotide polymorphisms associated with cytoplasmic type and variable numbers of tandem repeats, possibly resulting from slipped-strand mispairing. Our observations support the use of chloroplast-specific markers to assist in the selection of specific cytoplasmic types, suggest the potential to facilitate genotype determination, and demonstrate the presence of additional variation within cytoplasm type which gives insight into plastome evolution and may facilitate more accurate genotyping and selection.
\end{abstract}

The chloroplast genome (plastome) of plants exists as a single circular chromosome ranging from 120 to $217 \mathrm{~kb}$ in length (Palmer, 1987). The plastome is organized into two single-copy regions (large and small) separated by an inverted repeat. Much of the size variation between species is accounted for by variation in the size of the inverted repeat. The structure and gene content of the chloroplast genome is well conserved among plants, with the exception of one group of legumes, who are missing the inverted repeat (Palmer, 1987). The chloroplast genome also exhibits a conservative rate of nucleotide substitution relative to plant nuclear genes (Clegg and Zurawski, 1992). This relatively low evolutionary rate of the cpDNA has made it an ideal tool to study plant systematics and evolution above the species level (Palmer, 1987; Palmer et al., 1988; Soltis et al., 1992).

Despite the low evolutionary rate of the chloroplast genome, intraspecific chloroplast DNA (cpDNA) variation has been documented in a wide array of plant families (Soltis et al., 1992). The genetic nature of intraspecific cpDNA variation is typically limited to base substitution changes and insertion-deletion mutations (Soltis et al., 1992). It has been observed that there is a high incidence of sequence length mutation within single species. However, species differ considerably in the occurrence of length mutations versus base substitutions. The prevalence of length variation may provide insights into evolutionary processes within and among populations (Jordan et al., 1996; Soltis et al., 1992).

The plant mitochondrial genome differs from that of other higher eukaryotes by its large genome size, variability, and pres-

Received for publication 24 June 1998. Accepted for publication 3 Dec. 1998. We gratefully acknowledge the technical assistance of Roger Horn and Avutu S. Reddy. Richard W. Jones (Asgrow Vegetable Seeds, Saticoy, Calif.) is acknowledged for providing genotypes $1630 \mathrm{~A}$ and TEG $951 \mathrm{C}$. J. Alcalá was funded through an assistantship from the Vegetable Improvement Center. Use of trade names does not imply endorsement of the products named nor criticism of similar ones not named. The cost of publishing this paper was defrayed in part by the payment of page charges. Under postal regulations, this paper therefore must be hereby marked advertisement solely to indicate this fact.

${ }^{1}$ Graduate research assistant.

${ }^{2}$ Professor.

${ }^{3}$ Associate professor; to whom reprint requests should be addressed. ence of large direct repeats and consequent multipartite structure (Mackenzie et al., 1994). Numerous abnormalities, including duplication of partial sequences of known coding regions, presence of chloroplast sequences, and evidence of unusual recombination events are also present (Lonsdale, 1989). Mitochondrial DNA (mt DNA) recombination events that occur among homologous repeated sequences as well as among apparently nonhomologous sequences result in a highly variable genome configuration in higher plants relative to other eukaryotic systems (Mackenzie et al., 1994). Some of these rearrangements are associated with cytoplasmic male sterility (Lonsdale, 1989).

It has been demonstrated that substoichiometric DNA fragments (sublimons) are present in low abundance relative to the main mtDNA. Sublimons have been detected in wheat (Triticum sp.) (Kück et al., 1993), maize (Zea maize L.) (Small et al., 1987, 1989), and Brassica mtDNA (Shirdazegan et al., 1989). Recent evidence suggests that these substoichiometric molecules may be the substrates for which new mitochondrial genomic configurations are generated (Hanson and Folkerts, 1992). Similar observations of substoichiometric organelle DNA organizations have been observed in chloroplasts of higher plants (Moon et al., 1987) and in animal mitochondria (Hauswirth and Laipis, 1986).

Sublimons may be maintained and passed from generation to generation through maternal inheritance and may differentially accumulate in specific progeny and populations (Small et al., 1989). According to Leaveretal. (1988) persistent substoichiometric fragments could provide a means for rapid cryptic genome evolution, only revealed in subsequent generations by transmission, amplification, and resulting fixation. Nuclear genes can also have an influence on the amplification or loss of subgenomic circular mtDNAs as demonstrated previously in Zea and Phaseolus (Covello and Gray, 1991; Escote-Carlson et al., 1990).

Cytoplasmic male sterility (CMS) is a common trait in many plant species, controlled at least in part by cytoplasmically inherited genes, and results in the inability of a plant to shed or produce viable pollen (Hanson and Conde, 1985; Laughnan and GabayLaughnan, 1983). CMS is agriculturally valuable for the production of hybrid seed by allowing for controlled pollination and 
eliminating the need for hand emasculation.

In onion (Allium cepa), two types of cytoplasmic male sterility have been described. Cytoplasmic male sterility type $\mathrm{T}$ was discovered in the onion cultivar Jaune Paille des Vertus (Berninger, 1965) and is controlled by a cytoplasmic determinant [T] and three independently segregating restorer loci (Schweisguth, 1973). Cytoplasmic male-sterility type $\mathrm{S}$ was discovered in the onion cultivar Italian Red and is conditioned by the interaction of the cytoplasm (sterile, [S]) with a single recessive male-fertility nonrestoring allele ( $m s$ ). (Jones and Emsweller, 1936). Hybrid onion production primarily relies on CMS type $\mathrm{S}$ because of the simpler inheritance of fertility restoration (Jones and Clarke, 1943).

Although the biochemical and genetic bases underlying CMS are not well understood (Hanson and Conde, 1985; Levings, 1983, 1993), this trait has been associated with changes in the genomes of the mitochondria and chloroplast (Boeshore et al., 1983; Conde et al., 1982; Levings and Pring, 1976, 1977; Pring et al., 1982). In onion, restriction patterns of chloroplast and mitochondrial DNA have permitted distinction between [S], [N], and [T] cytoplasms (Courcel et al., 1989; Havey, 1993; Holford et al., 1991; Satoh et al., 1993). Since the onion plasmon shows maternal inheritance, polymorphisms observed in the chloroplast genome can be used to identify [S] and [N] cytoplasms (Courcel et al., 1989; Havey, 1993; Holford et al., 1991; Satoh et al., 1993). Havey (1995) proposed the use of plastome-specific DNA amplification to distinguish between $[\mathrm{S}]$ and $[\mathrm{N}]$ cytoplasms and to aid in the identification of maintainer lines from open-pollinated populations.

The amplification of a noncoding chloroplast sequence (intergenic spacer) between $\operatorname{trn} \mathrm{T}$ (UGU) and $t r n \mathrm{~L}$ (UAA) in onion yields either a $1.0 \mathrm{~kb}$ or a $1.1 \mathrm{~kb}$ amplicon associated with [S] or [N] cytoplasm, respectively (Havey, 1995). Havey (1995) demonstrated that plants with [N] cytoplasm show a 100-bp insertion in the cpDNA. The use of the polymerase chain reaction (PCR) and chloroplast-specific primers have allowed rapid and accurate cytoplasm distinction. The utility of cytoplasm determination in onion breeding has been demonstrated previously by Havey (1995) and Alcala et al. (1997). Here we report DNA sequence variation within the intergenic spacer of different [N] cytoplasm breeding lines and as compared to [S] cytoplasm lines. DNA sequence variation was observed both as single base substitutions and the level of numbers of entire repeat sequences suggesting possible slip-strand mispairing during replication as one origin of variability. The observed sequence variation may be useful in the selection of specific cytoplasmic types and in the identification of genotypes.

\section{Materials and Methods}

Plant material. Onion seedlings were grown at $22^{\circ} \mathrm{C}$ for 2 weeks under fluorescent lights in MetroMix 700 (Kinney Bonded, Donna, Tex.). Two-week-old leaves were harvested and frozen immediately in liquid nitrogen and stored at $-80{ }^{\circ} \mathrm{C}$ until needed for DNA isolation.

DNa ISOlation AND ANALYSIs. Two-week-old leaf samples of 15 onion breeding lines (24 samples/line) were used to extract total DNA by the method of Fulton et al. (1995). Concentration was determined by agarose gel electrophoresis using known amounts of lambda DNA as standards and by UV spectrophotometry.

PCr ANd Gel electrophoresis. A \pm 1000 -bp cpDNA region (intergenic spacer between $\operatorname{trn} \mathrm{T}$ (UGU) and $t r n \mathrm{~L}$ (UAA) 5') was amplified by PCR using the oligonucleotides SM1 (5'CATTACAAATGCGATGCTCT-3') and SM2 (5'
TCTACCGATTTCGCCATATC-3') as primers (Havey, 1995) and amplification conditions as described previously (Alcala et al., 1997). Amplified DNAs were separated by agarose gel electrophoresis using neutral gel buffer and $1.5 \%$ agarose gels as in Fulton et al. (1995). The presence of a $1.0 \mathrm{~kb}$ or a $1.1 \mathrm{~kb}$ amplicon was used as an indicator of $[\mathrm{S}]$ or $[\mathrm{N}]$ cytoplasms, respectively. The appearance of an amplicon of different mobility compared to the controls prompted the sequencing and molecular analysis of additional breeding lines. Amplifications which when repeated twice and resulted in identical results were considered accurate.

DNa SEQuence analysis. Control clones, 1630 A ([S] cytoplasm, $1.0 \mathrm{~kb}$ amplicon) and TEG $951 \mathrm{C}([\mathrm{N}]$ cytoplasm, $1.1 \mathrm{~kb}$ amplicon) were cloned previously (Alcala et al., 1997). One clone per control was sequenced. Sequencing of the amplicon was performed using primers SM1, SM2, and SM3 (5'CTGGAAGGGTCGATATTCTTC-3') to encompass the entire region. To verify that the noncoding chloroplast region and singlenucleotide polymorphisms (SNPs) were conserved among several genetic backgrounds, and that the sequences accurately reflect the majority of sequences in the respective plastomes, seven [N] cytoplasmic lines and six [S] cytoplasmic lines (1 plant/line) were amplified with primers SM1 and SM2 and the resulting amplified products were directly sequenced without cloning. Direct sequencing of the PCR products will not reflect rare sequence nor errors resulting from polymerase misincorporation as such variants will represent only a small fraction of the larger pool even if generated in early rounds of amplification. Sequencing was performed on an ABI 377 automated sequencer (Perkin Elmer, Norwalk, Conn.) with fluorescent labeling reagents and protocols provided by Invitrogen (Carlsbad, Calif.).

\section{Results}

The sequencing of amplicons of lines $1630 \mathrm{~A}$ and TEG $951 \mathrm{C}$ revealed that these fragments were 1088 and 1184 bp long, (GenBank accession numbers AF007065 and AF007066) respectively (Fig. 1). The [S] cytoplasm control and all six [S] cytoplasm lines tested had identical sequence over the entire amplicon and all seven yielded agarose gel bands of identical size. Cytoplasmic classification of $[\mathrm{N}]$ cytoplasm onion lines via electrophoretic mobility in agarose gels also revealed a third uniquely sized amplicon of $1141 \mathrm{bp}$ (Fig. 1) present in the fertile [N] cytoplasm

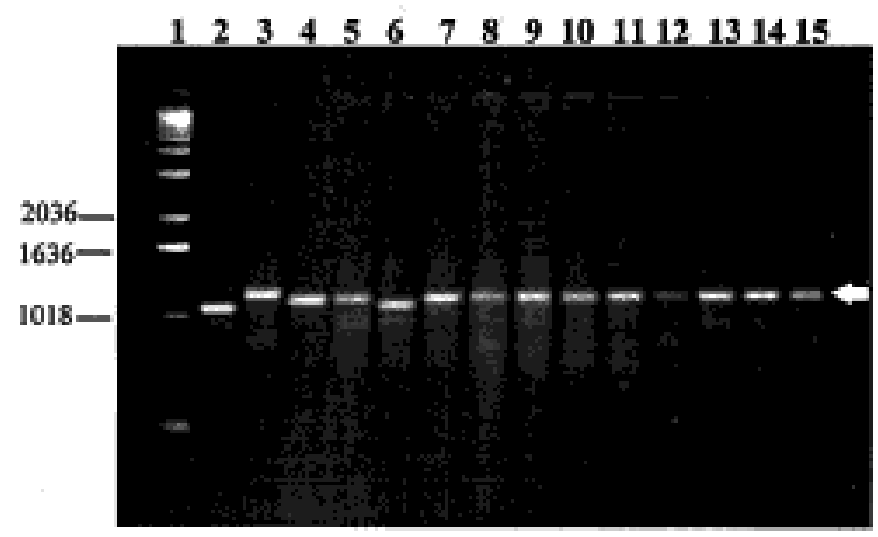

Fig. 1. Specific amplification of onion DNA using primers SM1 and SM2. Lane 1: 1-kb DNA ladder (Life Technologies). Lanes 2-3: [S] and [N] cytoplasm controls. Lanes 4-15: 12 onion plants from breeding line Dorada X Kadavan showing $[\mathrm{S}]$ and $[\mathrm{N}]$ cytoplasms. Note that plants 4, 5, 7, 8, 9, 10, 11, 12, 13, 14, and 15 possess a different amplification product. Arrow denotes novel cytoplasm size fragment. 
of two short-day onion cultivars, Dorada and Perla (GenBank accession numbers AF011392 and AF011393, respectively). It is important to note that sequence variation in the actual amplicon priming sites would not have been detected.

Several notable differences were observed between [S] and [N] plastome variants. Four single-nucleotide polymorphisms (SNPs 1, 3, 4, and 5) associated with cytoplasmic type were observed between controls $1630 \mathrm{~A}$ and TEG $951 \mathrm{C}$ (Table 1, Fig. 2). The four SNPs observed in the control lines were also conserved as differences among all $[\mathrm{S}]$ versus $[\mathrm{N}]$ lines screened, thus confirming the association of the single-nucleotide differences with [S] and [N] cytoplasms in onion. Cultivars Dorada and Perla shared one nucleotide polymorphism, SNP2, which was exclusive to these cultivars (Table 1, Fig. 2). In addition, a single base-pair substitution (SNP 6) was found to be exclusive to 'Dorada'.

Sterile and normal plastome variants also differed in the number and position of tandem repeats. Tandem repeat 1 was present twice in all [S] cytoplasmic lines whereas both [N] cytoplasmic variants showed only one copy (Table 1, Fig. 2). However, sequence analysis of seven breeding lines classified with [N] cytoplasm through conventional cytoplasmic screening (Table 1) (Havey, 1995) showed that three unique tandem repeats (TR 2; 45, 45 , and 42 bp long, respectively) were present in five of the lines whereas [S] cytoplasmic lines showed only one repeat 42 bp long (Fig. 2). Interestingly, [N] cytoplasm cultivars Dorada and Perla showed only two repeats (45 and $42 \mathrm{bp}$ ) instead of three repeats typical of the other five cultivars with [N] cytoplasm (Table 1, Fig. 2 ). The presence of additional tandem repeats in cultivars with [N] cytoplasm accounted for the majority of the difference in the fragment sizes observed between $[\mathrm{N}]$ cytoplasmic variants and among $[\mathrm{S}]$ and $[\mathrm{N}]$ cytoplasmic lines. A third tandem repeat (TR3) was observed in all cultivars. This repeat was $17 \mathrm{bp}$ long and was present twice in all cultivars with [N] cytoplasm (Table 1, Fig. 2). Cultivars with [S] cytoplasm showed this repeat only once.

In summary, four single nucleotide polymorphisms distinguished all $[\mathrm{N}]$ from all $[\mathrm{S}]$ cytoplasm types analyzed. One additional single nucleotide polymorphism distinguished the two [N] cytoplasmic types. In addition, tandem repeat sequences served as more robust indicators of plastome variation. Tandem repeat 1 occurred as two copies in all [S] cytoplasm lines tested and one copy in all $[\mathrm{N}]$ cytoplasm lines. Conversely, tandem repeat 3 occurred as two copies in all $[\mathrm{N}]$ cytoplasm lines and one copy in all [S] cytoplasm lines. The largest repeat, tandem repeat 2, also varied among all $[\mathrm{S}]$ cytoplasm (1 copy) versus $[\mathrm{N}]$ cytoplasm lines, however there was internal variation in $[\mathrm{N}]$ cytoplasm with two lines harboring two copies of this repeat while the remaining five lines each contained three copies (Fig. 2).

\section{Discussion}

Plastome variation as a basis for cytoplasm Selection. Chloroplast DNA is frequently used in systematic studies of species divergence (Palmer, 1987) and has been useful in elucidating evolutionary relationships within and among populations (Soltis et al., 1992; Wagner et al., 1987). The chloroplast genome has been reported to show a lower average mutation rate than specific regions of plant or animal nuclear DNA (Wolfe et al., 1987). Although it has been suggested that the chloroplast genome shows a low evolutionary rate, the noncoding regions of the plastome tend to evolve more rapidly than do coding regions (Clegg et al., 1991; Palmer et al., 1988; Wolfe et al., 1987).

In this study, sequence analysis of approximately $1 \mathrm{~kb}$ of a noncoding chloroplast genome region between tRNA genes allowed for the distinction of one sterile and two normal plastome variants in onion. The sequence information of the different plastomes obtained in this study is similar to that obtained by Taberlet et al. (1991) who used the same universal primers (SM1 and SM2) to successfully amplify cpDNA noncoding regions over a wide taxonomic range.

Several single-nucleotide polymorphisms and variable numbers of tandem repeat sequences of 8 to $45 \mathrm{bp}$ associated with cytoplasmic type were characterized in fifteen onion breeding

Table 1. Molecular differences of a noncoding chloroplast intergenic spacer region between $\operatorname{trn} T$ and $\operatorname{trn} L$ among short-day onion breeding lines.

\begin{tabular}{|c|c|c|c|c|c|c|c|c|c|c|}
\hline \multirow{2}{*}{$\begin{array}{l}\text { Breeding } \\
\text { line }\end{array}$} & \multirow[b]{2}{*}{ Cytoplasm } & \multicolumn{3}{|c|}{$\begin{array}{l}\text { Tandem repeat }{ }^{2}(\mathrm{TR}) \\
\text { (no. copies) }\end{array}$} & \multicolumn{6}{|c|}{$\begin{array}{c}\text { Single nucleotide } \\
\text { polymorphism }(\mathrm{SNP})^{\mathrm{y}}\end{array}$} \\
\hline & & TR 1 & TR 2 & TR 3 & SNP1 & SNP2 & SNP3 & SNP4 & SNP5 & SNP6 \\
\hline TEG 951 C & {$[\mathrm{N}]$} & 1 & 3 & 2 & $\mathrm{C}$ & $\mathrm{G}$ & $\bar{T}$ & $\mathrm{G}$ & $\mathrm{A}$ & $\bar{T}$ \\
\hline Dorada $^{\mathrm{x}} \times$ Kadavan & {$[\mathrm{N}]$} & 1 & 2 & 2 & $\mathrm{C}$ & A & $\mathrm{T}$ & $\mathrm{G}$ & A & $\mathrm{C}$ \\
\hline Perla $^{\mathrm{x}} \mathrm{x}$ Kadavan & {$[\mathrm{N}]$} & 1 & 2 & 2 & $\mathrm{C}$ & A & $\mathrm{T}$ & G & A & $\mathrm{T}$ \\
\hline Chona $\times(\beta \alpha$ Yellow $\times$ Ringold $)$ & {$[\mathrm{N}]$} & 1 & 3 & 2 & $\mathrm{C}$ & G & $\mathrm{T}$ & G & A & $\mathrm{T}$ \\
\hline Ben Shemen x TG 502 & {$[\mathrm{~N}]$} & 1 & 3 & 2 & $\mathrm{C}$ & $\mathrm{G}$ & $\mathrm{T}$ & $\mathrm{G}$ & $\mathrm{A}$ & $\mathrm{T}$ \\
\hline$(\beta \alpha$ White $\times$ NMYG $) \times$ TG $1015 \mathrm{Y}^{\mathrm{x}}$ & {$[\mathrm{N}]$} & 1 & 3 & 2 & $\mathrm{C}$ & G & $\mathrm{T}$ & $\mathrm{G}$ & A & $\mathrm{T}$ \\
\hline Ringer X TG $1015 \mathrm{Y}$ & {$[\mathrm{N}]$} & 1 & 3 & 2 & $\mathrm{C}$ & G & $\mathrm{T}$ & $\mathrm{G}$ & A & $\mathrm{T}$ \\
\hline TG $1015 \mathrm{~W}$ & {$[\mathrm{~N}]$} & 1 & 3 & 2 & $\mathrm{C}$ & G & $\mathrm{T}$ & $\mathrm{G}$ & A & $\mathrm{T}$ \\
\hline $1630 \mathrm{~A}$ & {$[\mathrm{~S}]$} & 2 & 1 & 1 & A & G & A & $\mathrm{T}$ & G & --- \\
\hline TG 1015 Y x Ringer & {$[\mathrm{S}]$} & 2 & 1 & 1 & A & $\mathrm{G}$ & A & $\mathrm{T}$ & $\mathrm{G}$ & --- \\
\hline TG 502-2 x $4172 \mathrm{RB}$ & {$[\mathrm{S}]$} & 2 & 1 & 1 & A & G & A & $\mathrm{T}$ & G & --- \\
\hline Ringold Yellow Selection & {$[\mathrm{S}]$} & 2 & 1 & 1 & A & $\mathrm{G}$ & A & $\mathrm{T}$ & $\mathrm{G}$ & --- \\
\hline Texas Early White ${ }^{\mathrm{x}}$ x TG $1015 \mathrm{Y}$ & {$[\mathrm{S}]$} & 2 & 1 & 1 & A & $\mathrm{G}$ & A & $\mathrm{T}$ & $\mathrm{G}$ & --- \\
\hline TG $1025-85 \times$ TG $1025^{x}$ & {$[\mathrm{~S}]$} & 2 & 1 & 1 & A & G & A & $\mathrm{T}$ & G & --- \\
\hline Kadavan $x$ Perla & {$[\mathrm{S}]$} & 2 & 1 & 1 & A & G & A & $\mathrm{T}$ & $\mathrm{G}$ & --- \\
\hline
\end{tabular}

'TR 1 = tandem repeat of 8 bp (5'-CTTTTAGA-3') 31 bp from primer SM2; TR 2 = tandem repeat of 42 to 45 bp (5'GGACTGATCCGCTATAATATGAATATAATTAATCTTATTTGTTTA-3') 49 bp from primer SM2; TR $3=$ tandem repeat of 17 bp (5'TATATTATTAATATTAA-3') 839 bp from primer SM2 in genotype 1630 A (Fig. 2).

${ }^{\mathrm{y}} \mathrm{SNP} 1=142 \mathrm{bp}$ from primer SM2, SNP2 = 178 bp from primer SM2, SNP3 = 618 bp from primer SM2, SNP4 = 633 bp from primer SM2, SNP5 = 697 bp from primer SM2, SNP6 = 924 bp from primer SM2 (Fig. 2).

xPlant variety protected cultivars developed by the Texas A\&M Onion Breeding Program. 
1184 bp fragment (N cytoplusu)

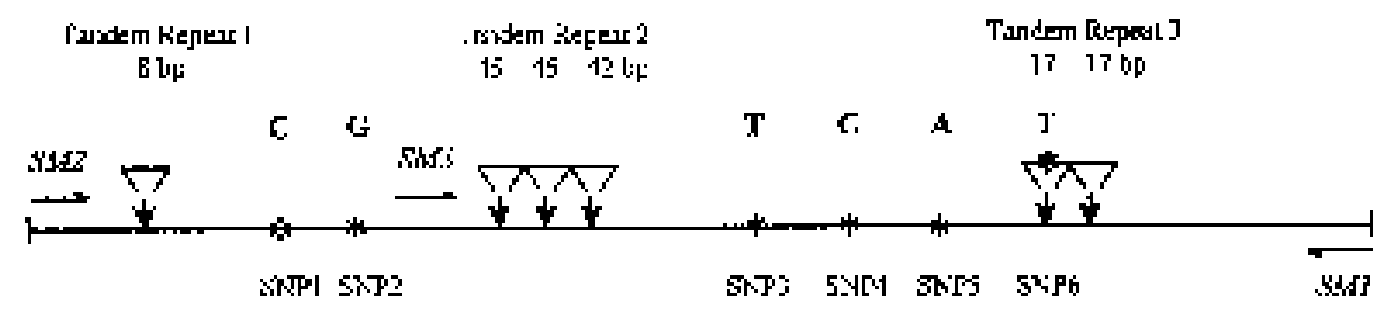

1141 bp fragment, corresponding to tuliviss Dhorada and Perta (N ç̧toplasm)

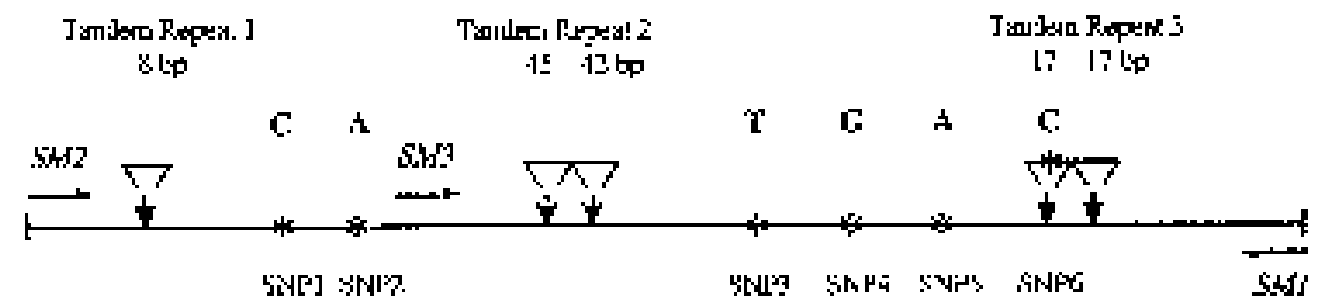

1088 lop fragment (Si cỵtoplasm)

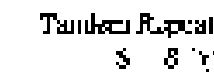

3 8 R:

Tundreו Гrep:al 2

4390
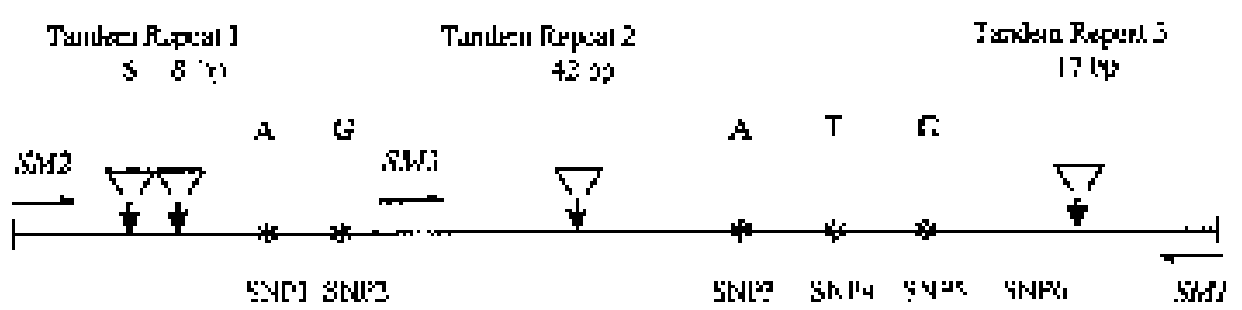

-cytoplasm, seven lines with [S] cytoplasm) to identify differences among plastome variants. However, as all differences (except for one single base substitution between two $[\mathrm{N}]$ cytoplasm lines) were observed identically in individuals from two or more distinct lines it is highly probable that they are representative of intraspecific variation. Indeed the four single nucleotide polymorphisms and the variation in tandem repeat numbers for tandem repeats 1 and 3 were identical among the individuals examined from all $[\mathrm{S}]$ versus $[\mathrm{N}]$ cytoplasm lines and thus can be considered reliable indicators of intraspecific variation in the onion cpDNA. The identification of identical variation in copy number of tandem repeat 2 for two of the [N] cytoplasm lines (Dorada and Perla) relative to the remaining five $[\mathrm{N}]$ lines is also significant as 1) identical single plant genetic alteration in individuals from two distinct lines is highly improbable, 2) both lines are derived from a common parent, and 3) 24 individuals each of 'Dorada' and 'Perla' were amplified with primers SM1 and SM3 and yielded identically sized bands to those derived from the sequenced 'Dorada' and 'Perla' individuals. Since the shift in gel mobility observed among [N] cytoplasm lines is due to the variation in tandem repeat 2 copy number, this assay is a highly reliable indicator of identical tandem repeat copy number in all 48 individuals. Thus, in total 25 of 25 individuals from 'Dorada' and 'Perla' were shown to have one less copy of tandem repeat 2 than 25 individuals each from the other $5[\mathrm{~N}]$ cytoplasm lines tested based on PCR (data not shown).

Possible ORIgINS OF DNA VARIATION IN THE ONION TRNT-TRNF REGION. Addition-deletion mutations accumulate in noncoding regions at a rate that is at least equal to nucleotide substitution, accelerating the divergence of noncoding regions (Clegg and Zurawski, 1992). Many addition-deletion mutations are associated with short direct repeats, and probably arise from slippedstrand mispairing during replication (Takaiwa and Sugiura, 1982; Clegg and Zurawski, 1992). Due to the association of additiondeletion mutation with direct repeats, it has been suggested that particular noncoding regions may experience higher rates of these mutations because of local sequence features (Clegg and Zurawski, 1992). Therefore, the noncoding region between the $\operatorname{trnT}$ (UGU) and $\operatorname{trn} F(\mathrm{GAA})$ genes in the large single-copy region of onion may be prone to addition-deletion mutations as evidenced by the appearance of several tandem repeats (e.g., tandem repeat 2).

The short-day onion cultivar Dorada was developed from one self-pollinated bulb out of the cultivar Ben Shemen (R. Jones, 
personal communication). This selected population showed many desirable characteristics when compared to the original 'Ben Shemen' and also showed segregation for color (white vs. yellow bulbs). This family was massed consecutively five times using selected yellow bulbs from each mass. The few white segregates present in the third mass of 'Dorada' were used to develop 'Perla'. The fact that these two lines share a common plastome variation in terms of tandem repeat 2 copy number in the noncoding intergenic spacer region is thus not surprising.

The plant mitochondrial genome is characterized by a multipartite structure (substoichiometric molecules known as sublimons) due to the active recombination between pairs of repeated DNA sequences (Leaver et al., 1988). Similar observations of substoichiometric organelle DNA organizations have been observed in chloroplasts of higher plants (Moon et al., 1987). The mitochondrial sublimons are generally stable and inherited from generation to generation (Lonsdale et al., 1984) and presumably the same would be true of plastome sublimons. A possible explanation for the appearance of TR2 in cultivars Dorada and Perla could be that the mutation giving rise to this repeat (probably by slipped-strand mispairing) is present on chloroplast sublimons. Since these substoichiometric DNA fragments are present at relatively low levels, mutational events in one of these molecules can eventually affect a relatively high proportion of the sublimon population (random genetic drift) (Leaver et al., 1988). Such sublimons could have become prevalent and eventually become fixed and amplified in the 'Dorada' and 'Perla' selections regardless of their genetic background (Leaver et al., 1988). Nevertheless, if the variant sequences observed among any of the lines examined were due to the presence of sequences known to exist on the plastome but duplicated on sublimons, the method of DNA sequencing used (direct sequencing of PCR products without cloning of individual amplicons) would have yielded overlapping (nonscoreable) sequences from the position of the missing repeat onward as both the plastome and hypothetical sublimon would have been simultaneously sequenced. Rather, the method of DNA sequence generation employed confirms that the variant sequences observed represent prevalent plastome DNA forms. In summary, the best explanation for the observed differences in intergenic spacer sequence among [N] cytoplasm lines is slipped-strand mispairing during replication of plastome DNA in an ancestor predating the split of the Dorada and Perla lines.

Depending on when this variation occurred one might predict that the noncoding chloroplast region of 'Ben Shemen' might contain an identical sequence variation. Ben Sheman was thus also analyzed for this variable region (Table 1, Fig. 2) and did not show the two exclusive tandem repeats of 'Dorada' and 'Perla' but showed instead three repeats commonly observed in other cultivars with $[\mathrm{N}]$ cytoplasm. The SNPs specific to 'Dorada' and 'Perla' were also not found in 'Ben Shemen'. One possible explanation for this observation could be that the 'Ben Shemen' seed stock used for this experiment was of a different source from the original stock from which 'Perla' and 'Dorada' were selected. Additionally, the original 'Ben Shemen' seed stock from which one self-pollinated bulb was selected to originate 'Dorada' and 'Perla' could have contained heterogeneous mixtures of plastomes. Therefore, with consecutive masses, plastomes with two copies of TR2 could have become fixed and amplified in the progeny populations. Finally, the sequence variation resulting in the DoradaPerla variation may have arisen in or shortly after the original selection from Ben Sheman. The fact that as few as a single plastid can be transmitted through the ovule would allow for rapid fixation of a plastome variant (Mullet, 1988). Regardless of when the variation arose it is a clear fingerprint of these two lines.

In summary, intraspecific cpDNA variation has been observed among populations, within populations, and within individual plants. It has been suggested that the prevalence of intraspecific variability in the chloroplast genome has been underestimated (Soltis et al., 1992). The results of this study suggest that intraspecific cpDNA variation in onion may be common and worth analyzing using noncoding chloroplast sequences. Unique sequences that flank the tandem repeats can potentially be used as targets or for making highly polymorphic PCR-based markers (Burr, 1994). Chloroplast intraspecific polymorphisms could be useful to classify onion cultivars by cytoplasmic type (Alcala et al., 1997 ) and to fingerprint or pedigree onion genotypes.

\section{Literature Cited}

Alcala, J., J.J. Giovannoni, L.M. Pike, and A.S. Reddy. 1997. Application of Genetic Bit Analysis (GBA) for allelic selection in plant breeding. Mol. Breeding 3:495-502.

Banks, J.A. and C.W. Birky, Jr. 1985. Chloroplast DNA diversity is low in a wild plant, Lupinus texensis. Proc. Natl. Acad. Sci. USA 82:69506954.

Berninger, E. 1965. Contribution a l'etude de la sterilite-male de l'oignon (Allium cepa L.). Ann. Amelior. Plantes 15(2):183-199.

Boeshore, M.L., I. Lifshitz, M.R. Hanson, and S. Izhar. 1983. Novel composition of mitochondrial genomes in Petunia somatic hybrids derived from cytoplasmic male sterile and fertile plants Petunia hybrida. Mol. Gen. Genet. 190:459-467.

Burr, B. 1994. Some concepts and new methods for molecular mapping in plants, p. 1-7. In: R.L. Phillips and I.K. Vasil (eds.). DNA-based markers in plants. Kluwer Academic Publishers, Netherlands.

Clegg, M.T., G.H. Learn, and E.M. Golenberg. 1991. Molecular evolution of chloroplast DNA, p. 135-149. In: R.K. Selander, A.G. Clark, and T.S. Whittman (eds.). Evolution at the molecular level. Sinauer Assoc., Sunderland, Mass.

Clegg, M.T. and G. Zurawski. 1992. Chloroplast DNA and the study of plant phylogeny: Present status and future prospects, p. 1-13. In: P.S. Soltis, D.E. Soltis, and J.J. Doyle (eds.). Molecular systematics of plants. Chapman and Hall, New York.

Conde, M.F., D.R. Pring, K.F. Schertz, and W.M. Ross. 1982. Correlation of mitochondrial DNA restriction endonuclease patterns with sterility expression in six male-sterile sorghum cytoplasms. Crop Sci. 22(3):536539.

Courcel de, A.G.L., F. Vedel, and J.M. Boussac. 1989. DNA polymorphism in Allium cepa cytoplasms and its implications concerning the origin of onions. Theor. Appl. Genet. 77:793-798.

Covello, P.S., and M.W. Gray. 1991. Sequence analysis of wheat mitochondral transcripts capped in vitro: Definitive identification of transcription initiation sites. Curr. Genet. 20:245-251.

Doebly, J. 1989. Molecular evidence for a missing wild relative of maize and the introgression of its chloroplast genome into Zea perennis. Evolution 43:1555-1559.

Escote-Carlson, L.J., S. Gabay-Laughnan, and J.R. Laughnan. 1990. Nuclear genotype affect mitochondrial genome organization of CMS-S maize. Mol. Gen. Genet. 223:457-464.

Fulton, T.M., J. Chunwongse, and S.D. Tanksley. 1995. Miniprep protocol for extraction of DNA from tomato and other herbaceous plants. Plant Mol. Biol. 13:207-209.

Govindaraju, D.R., D.B. Wagner, G.P. Smith, and B.P. Dancik. 1988. Chloroplast DNA variation within individual trees of a Pinus banksianaPinus contorta sympatric region. Can. J. For. Res. 18:1347-1350.

Hanson, M.R. and M.F. Conde. 1985. Functioning and variation of cytoplasmic genomes: Lessons from cytoplasmic-nuclear interactions affecting male fertility in plants. Intl. Rev. Cytol. 94:213-267.

Hanson, M.R. and O. Folkerts. 1992. Structure and function of the higher plant mitochondrial genome. Intl. Rev. Cytol. 141:129-172.

Hauswirth, W.W. and P.J. Laipis. 1986. Transmission genetics of mammalian mitochondria: A molecular model and experimental evidence, $p$. 
49-59. In: E. Quagliariello, E.C. Slater, F. Palmieri, C. Saccone, and A.M. Kroon (eds.). Achievements and perspectives of mitochondrial research. vol. 2 (Biogenesis). Elsevier Science Publishers, Amsterdam, New York.

Havey, M.J. 1993. A putative donor of S-cytoplasm and its distribution among open-pollinated populations of onion. Theor. Appl. Genet. 86:128-134.

Havey, M.J. 1995. Identification of cytoplasms using the polymerase chain reaction to aid in the extraction of maintainer lines from openpollinated populations of onion. Theor. Appl. Genet. 90:263-268.

Holford, P., J.H. Croft, and H.J. Newbury. 1991. Differences between, and possible origins of, the cytoplasms found in fertile and male-sterile onions (Allium cepa L.). Theor. Appl. Genet. 82:737-744.

Johnson, L.B. and J. D. Palmer. 1989. Heteroplasmy of chloroplast DNA in Medicago. Plant Mol. Biol. 12:3-11.

Jones, H.A. and S.L. Emsweller. 1936. A male-sterile onion. Proc. Amer. Soc. Hort. Sci. 34:582-585.

Jones, H.A. and A.E. Clarke. 1943. Inheritance of male sterility in the onion and the production of hybrid seed. Proc. Amer. Soc. Hort. Sci. 43:189-194.

Jordan, W.C., M.W. Courtney, and J.E. Neigel. 1996. Low levels of intraspecific genetic variation at a rapidly evolving chloroplast DNA locus in North American duckweeds (Lemnaceae). Amer. J. Bot. 83:430 439.

Kück, U., S. Mohr, B. Laser, E. Schulte-Kappert, W. Odenbach, and G. Oettler. 1993. Nuclear-mitochondrial interactions in Triticum and Triticale, p. 357-366. In A. Brennicke and U. Kück (eds.). Plant Mitochondria. VCH Publishers, New York, NY.

Laughnan J.R. and S. Gabay-Laughnan. 1983. Cytoplasmic male sterility in maize. Annu. Rev. Genet. 17:27-48.

Leaver, C.J., P.G. Isaac, I.D. Small, J. Bailey-Serres, A.D. Liddell, and M.J. Hawkesford. 1988. Mitochondrial genome diversity and cytoplasmic male sterility in higher plants. Philos. Trans. R. Soc. Lond. 319:165-176.

Levings, C.S. 1983. Cytoplasmic male sterility in higher plants, p. 81-92. In: T. Kosuge and C.P. Meredith (eds.). Genetic engineering of plants: An agricultural perspective. Plenum Press, New York.

Levings, III, C.S. 1993. Thoughts on cytoplasmic male sterility in cms-T maize. Plant Cell 5:1285-1290.

Levings, III, C.S. and D.R. Pring. 1976. Restriction endonuclease analysis of mitochondrial DNA from normal and Texas cytoplasmic male-sterile maize. Science 193:158-160.

Levings, III, C.S. and D.R. Pring. 1977. Diversity of mitochondrial genomes among normal cytoplasms of maize. J. Hered. 68:350-354.

Lonsdale, D.M. 1989. The plant mitochondrial genome, p. 229-295. In: A. Marcus (ed.). The biochemistry of plants: A comprehensive treatise. vol 15. Academic Press, New York.

Lonsdale, D.M., T.P. Hodge, and C.M.R. Fauron. 1984. The physical map and organization of the mitochondrial genome from the fertile cytoplasm of maize. Nucl. Acids Res. 12:9249-9261.
Mackenzie S., S. He, and A. Lyznik. 1994. The elusive plant mitochondrion as a genetic system. Plant Physiol. 105:775-780.

Moon, E., T.H. Kao, and R. Wu. 1987. Rice chloroplast DNA molecules are heterogeneous as revealed by DNA sequences of a cluster of genes. Nucl. Acids Res. 15:611-630.

Mullet, J. 1988 Chloroplast development and gene expression. Annu. Rev. Plant Physiol. Plant Mol. Biol. 39:475-502.

Palmer, J.D. 1987. Chloroplast DNA evolution and biosystematic uses of chloroplast DNA variation. Amer. Naturalist 130:S6-S29.

Palmer, J.D., R.K. Jansen, H.J. Michaels, M.W. Chase, and J.R. Manhart. 1988. Chloroplast DNA variation and plant phylogeny. Ann. Miss. Bot. Gar. 75:1180-1206.

Palmer, J.D., R.A. Jorgensen, W.F. Thompson. 1985. Chloroplast DNA variation and evolution in Pisum: Patterns of change and phylogenetic analysis. Genet. 109:195-213.

Pring, D.R., M.F. Conde, and K.F. Schertz. 1982. Organelle genome diversity in sorghum: Male-sterile cytoplasms Sorghum bicolor. Crop Sci. 22:414-421.

Satoh, Y., M. Nagai, T. Mikami, and T. Kinoshita. 1993. The use of mitochondrial DNA polymorphism in the classification of individual onion plants by cytoplasmic genotypes. Theor. Appl. Genet. 86:345-348. Schweisguth, B. 1973. Etude d'un nouveau type de sterilite male chez l'oignon, Allium cepa L. Ann. Amelior. Plantes 23(3):221-233.

Shirdazegan, M., M. Christey, E.D. Earle, and J.D. Palmer. 1989. Rearrangement, amplification, and assortment of mitochondrial DNA molecules in cultured cells of Brassica campestris. Theor. Appl. Genet. 77:17-25.

Small, I., P.G. Isaac, and C.J. Leaver. 1987. Stoichiometric differences in DNA molecules containing the atpA gene suggest mechanisms for the generation of mitochondrial genome diversity in maize. EMBO J 6:865869.

Small, I., R. Suffolk, and C.J. Leaver. 1989. Evolution of plant mitochondrial genomes via substoichiometric intermediates. Cell 58:69-76.

Soltis, D.E., P.E. Soltis, and B.G. Milligan. 1992. Intraspecific chlroplast DNA variation: Systematic and phylogenetic implications, p. 117-150. In P.S. Soltis, D.E. Soltis, and J.J. Doyle (eds.). Molecular systematics of plants. Chapman and Hall, New York.

Taberlet, P., L. Gielly, G. Pautou, and J. Bouvet. 1991. Universal primers for amplification of three non-coding regions of chloroplast DNA. Plant Mol. Biol. 17:1105-1109.

Takaiwa, F. and M. Sugiura. 1982. The complete nucleotide sequence of a 23-S rRNA gene from tobacco chloroplasts Nicotiana tabacum. Eur. J. Biochem. 1:13-19

Wagner, D.B., G.R. Furnier, M.A. Saghai-Maroof, S.M. Williams, B.P. Dancik, and R.W. Allard. 1987. Chloroplast DNA polymorphisms in lodgepole and jack pines and their hybrids. Proc. Natl. Acad. Sci. USA 84:2097-2100.

Wolfe, K.H., W.H. Li, and P.M. Sharp. 1987. Rates of nucleotide substitution vary greatly among plant mitochondrial, chloroplast, and nuclear DNAs. Proc. Natl. Acad. Sci. USA 84:9054-9058. 